\title{
Pharmacotherapeutic follow-up of patients with Chagas disease using in use of benznidazole: drug-related problems and pharmaceutical interventions
}

\author{
João Paulo Ramalho Correia[1], Alanna Carla da Costa ${ }^{[1],[2], ~ E d u a r d o ~ A r r a i s ~ R o c h a ~}{ }^{[3]}$, \\ Ana Rosa Pinto Quidute ${ }^{[3]}$, Darlan da Silva Cândido ${ }^{[4]}$, Ângela Maria de Souza Ponciano ${ }^{[5]}$, \\ Marta Maria de França Fonteles ${ }^{[2],[5]}$ and Maria de Fátima Oliveira ${ }^{[1],[2]}$
}

\begin{abstract}
[1]. Laboratório de Pesquisa em Doença de Chagas, Departamento de Análises Clínicas, Universidade Federal do Ceará, Fortaleza, CE, Brasil. [2]. Programa de Pós-Graduação Stricto Sensu em Ciências Farmacêuticas, Universidade Federal do Ceará, Fortaleza, CE, Brasil.

[3] Hospital Universitário Walter Cantídio, Universidade Federal do Ceará, Fortaleza, CE, Brasil. [4]. Programa de Pós-Graduação Stricto Sensu em Alergia e Imunopatologia, Faculdade de Medicina, Universidade de São Paulo, São Paulo, SP, Brasil. [5]. Departamento de Farmácia, Centro de Estudos em Atenção Farmacêutica, Universidade Federal do Ceará, Fortaleza, CE, Brasil.
\end{abstract}

\begin{abstract}
Introduction: Benznidazole (BNZ) is a drug available for the etiological treatment of Chagas disease. However, this drug is toxic and has a limited effectiveness on the chronic phase of this disease, often leading to poor treatment adherence. Methods: This is a descriptive and exploratory study conducted at the Pharmaceutical Care Service for Chagas disease patients of the Federal University of Ceará. Drug-related problems (DRPs) and pharmaceutical interventions (PIs) were classified according to the Second Consensus of Granada. Results: The average age of patients with Chagas disease was 62 years, with the majority residing in the Ceará countryside (86.7\%), and having low education levels (63.3\% with elementary school education). Regarding family income, most patients belonged to a household that earned $\leq 1-2$ times the minimum wage per month. Approximately $73 \%$ of these patients complied with the BNZ treatment, and nearly $7 \%$ underwent therapy interruption after medical evaluation. A total of 189 DRPs were identified, of which $51.9 \%(n=98)$ were classified as potential, and $48.1 \%(n=91)$ as actual. The most frequent DRPs were related to safety (qualitative safety; $\mathrm{n}=70 ; 37 \%$ ), necessity (non-adherence; $\mathrm{n}=52 ; 27.5 \%$ ), and effectiveness (qualitative effectiveness/non-optimal drug selection; $\mathrm{n}=45 ; 23.8 \%$ ). Among the 216 PIs conducted, the majority were related to patient education $(n=168 ; 77.8 \%)$ and pharmacological strategy $(n=42 ; 19.4 \%)$. Conclusions: This study indicates the need for pharmacotherapeutic monitoring in patients with Chagas because of the high number of therapeutic interventions, DRPs (approximately $3 \mathrm{DRPs} /$ patient), BNZ adherence, and polypharmacy.
\end{abstract}

Keywords: Chagas disease. Pharmaceutical care. Pharmacotherapy.

\section{INTRODUCTION}

Chagas disease (CD), caused by the hemoflagellate protozoan Trypanosoma cruzi, is endemic to several Latin American countries. Over a century after its discovery, CD still presents as an important public health problem ${ }^{1}$. In fact, the epidemiological profile of $\mathrm{CD}$ has changed over the last decades, mainly because of migratory flow that led to both the urbanization and globalization of this disease ${ }^{2}$. According to the World Health Organization (WHO) in 2014, 7 to 8 million people were estimated to be infected worldwide, mainly in Latin America, where 75 to 90 million people are at risk of contracting the infection with over 10,000 deaths/year occurring from this

Corresponding author: Alanna Carla da Costa.

e-mail: alannacarla.costa@gmail.com

Received 21 November 2016

Accepted 2 June 2017 disease. In Brazil throughout almost all the states, approximately 3 million individuals are estimated to be infected with $\mathrm{CD}^{3-6}$.

Benznidazole (BNZ) is the only drug available for the etiological treatment of $\mathrm{CD}$ in Brazil. However, this drug is toxic and has a limited effectiveness in the chronic phase of the disease, often resulting in poor treatment adherence ${ }^{7,8}$. The 2015 Second Brazilian Consensus on Chagas Disease recommends treating all infected patients either during the early chronic and acute phase (regardless of the transmission routes), or those with undetermined, cardiac, and digestive forms (without serious clinical complications), or during the late chronic phase. BNZ treatment was also indicated in cases of transplantations, accidental infection, or in immunocompromised patients, in case reactivation occurs. Confirmed parasitological cure, especially during the chronic phase, depends on several factors, such as follow-up time and types of examinations conducted. During the treatment of CD, many drug-related problems (DRPs) may occur and interfere with the therapeutic results and patient quality of life ${ }^{9}$. 
Hepler and Strand ${ }^{10}$ created pharmaceutical care protocols that focus on patients, and aim to detect, prevent, and resolve DRPs. Upon analyzing pharmacist roles within the health care system, the WHO extended the benefit from this practice to the whole community, thus recognizing the role of pharmacists regarding the prevention of diseases, and promotion of health programs and statuses. Oftentimes, drugs fail or are unable to reach their expected therapeutic goals. Pharmacists, besides reviewing drug treatments, instruct patients in regards to the recommended drug dosage and design care plans based on the patients' needs. Further, an essential component of pharmaceutical care is pharmacotherapeutic follow-up, a process in which pharmacists are held accountable for the user/ patient needs related to specific drugs in an effort to achieve the expected results and improve the patient's quality of life ${ }^{10}$.

However, pharmacotherapeutic follow-up can contain several problems and challenges, such as treatment compliance and logging adverse reactions, including, those caused by drugs, and those involving therapy effectiveness and failure. DRP analysis requires pharmaceutical interventions that aim to change the characteristics of a treatment, patient, or conditions involved. In order to do so, a pharmacist must provide clinical advice about a patient's status and their treatment, thereby enabling physicians to make decisions with better knowledge and clarity ${ }^{11-13}$.

The follow-up of CD treatment with benznidazole is extremely necessary, although this is not often done in the care systems of the State of Ceará. However, this pharmacotherapeutic followup procedure was conducted by the Chagas Disease Research Laboratory (LPDC) of the Federal University of Ceará, Fortaleza, Ceará, Brazil. This pioneering service that has been active since 2005 aims to offer treatment, pharmacotherapeutic and laboratory monitoring to better meet the needs of patients with in Ceará.

Pharmacotherapeutic monitoring, such as the program performed by the LPDC, identifies, resolves, and prevents problems that may arise in CD therapy, as well as increase treatment adherence and effectiveness. In addition, pharmacotherapeutic monitoring is able to reduce adverse reactions and potential DRPs.

\section{METHODS}

\section{Study design}

This was a descriptive and exploratory study conducted on patients with $\mathrm{CD}$ in the Laboratory for Research in Chagas Disease (LPDC/UFC). After signing informed consent forms, 30 were enrolled for the monitoring period from January 2013 to May 2014. Patient records included complete and duly entered information. Interventions occurred at three different times: beginning of benznidazole therapy, 30 days after starting treatment, and 60 days after starting the treatment. Benznidazole was dispensed twice at the initial and 30 days post-visit.

During the initial therapeutic visit, the service team interviewed the patients and completed a pharmacotherapeutic follow-up form, from which data regarding lifestyle, sociodemographic factors, and drug therapy were collected.
The second visit occurred halfway during the treatment period, which was generally after 30 days.

Patients filled out (self-report) a list of undesirable effects from BNZ and interventions regarding the first step of treatment; however, interventions may have happened prior to the $30^{\text {th }}$ day depending on the severity of the complaints. A new evaluation of the list of undesirable effects was conducted 60 days after therapy was started, and the required interventions were conducted as necessary. A questionnaire on adherence and undesirable reactions was administered by the service team at 30 and 60 days to obtain further information from the patients.

DRPs and pharmaceutical interventions (PIs) were classified by a panel of specialists via case study discussions. According to the Second Consensus of Granada ${ }^{11}$, DRPs were classified as actual or potential, and then, as being related to necessity, effectiveness, or safety ${ }^{11}$. PIs were classified according to guidelines proposed by Sabater et al. ${ }^{14}$.

\section{Instruments used in the evaluation}

The following instruments were used in the evaluation: the Pharmacotherapeutic Follow-Up Questionnaire - an adaptation of the Dader Method - comprises of a first interview, situation analysis, and intervention phase ${ }^{12}$. During the patient interviews, researchers filled out pharmacotherapeutic sheets and recorded the following data: name, record number, sociodemographic data (gender, date and place of birth, etc.), and questions regarding clinical characteristics, medications, and lifestyles. Patients filled out undesirable reaction cards by checking the symptoms they experienced during their treatments. For illiterate patients, the researchers filled out their sheets according to their answers when they returned for the second visit. Compliance to BNZ treatment was analyzed based on a questionnaire adapted by Moreira et al, which consists of questions regarding patient behavior towards their prescriptions (number of tablets taken, number of tablets not taken, and reason for non-compliance). In addition, patients were asked to bring their remaining BNZ tablets to determine the number of tablets they had not taken. According to the data obtained, patients were classified as adherent or non-adherent. In order to determine whether a patient complied with their treatment, the equation proposed by Moreira et al, was used. This equation defines compliance as the ratio between the total tablets taken by a patient and the total tablets prescribed to be taken in the last 30 days. According to this calculation, patients are classified as adherent to treatments when they take at least $80 \%$ of their tablets. Patients below this rate were classified as non-adherent ${ }^{15}$.

\section{Classification of drug-related problems and pharmaceutical interventions}

Table 1 shows the classification used for recording and analyzing the DRPs according to the Second Consensus of Granada. All DRPs were recorded and analyzed regardless of their association to certain medication. DRPs that really occurred were considered actual, while DRPs that did not occur, but could have, were classified as potential ${ }^{11,12}$. The classification of PIs comprised three types of intervention: amount of medication, pharmacological strategy, and patient education ${ }^{14}$. 
TABLE 1

Classification of DRPs according to the Second Granada Consensus.

\begin{tabular}{ll}
\hline Category/classification & Description \\
\hline Necessity & $\begin{array}{l}\text { Patient has a health problem for not using the medication they need. } \\
\text { Patient has a health problem for using a medication they do not need. }\end{array}$ \\
\hline DRP 1 & $\begin{array}{l}\text { Patient has a health problem because of a non-quantitative ineffectiveness } \\
\text { of the medication. }\end{array}$ \\
\hline DRP 3 & $\begin{array}{l}\text { Patient has a health problem because of a quantitative ineffectiveness of } \\
\text { the medication. }\end{array}$ \\
\hline DRP 4 & $\begin{array}{l}\text { Patient has a health problem because of non-quantitative unsafety of the } \\
\text { medication. }\end{array}$ \\
\hline DRP 5 & $\begin{array}{l}\text { Patient has a health problem because of quantitative unsafety of the } \\
\text { medication. }\end{array}$ \\
\hline DRP 6 &
\end{tabular}

DRPs: drug-related problems. Source: Second Granada Consensus (2002) ${ }^{11}$.

\section{Ethical considerations}

This project complied with Brazil's National Health Council regulations (Directive CNS 466/12) governing human research and it was approved by the Federal University of Ceará's Research Ethics Committee (COMEPE-UFC), under protocol number 06081412.90000.5045.

\section{Statistical analysis}

Descriptive statistics were used to measure of the position and dispersion. Since the study evaluated nominal and ordinal variables, analyses classified as parametric and non-parametric were applied. The Student's $t$-test and Mann-Whitney U test were applied for the inferential analyses between the nominal and ordinal variables. Linear regression and Spearman's rank correlation coefficient were used for the inferential analyses of the quantitative variables. Fisher's exact test was used to evaluate the likelihood of association between the variable characteristics. In all tests, a significance level of 5\% was adopted.

\section{RESULTS}

\section{Sociodemographic and socioeconomic characteristics}

For the patients with $\mathrm{CD}$, the average age was 62-years, with most of these patients residing in the Cearás countryside (86.7\%), specifically from municipalities in the Jaguaribe valley region (Quixeré: 30\%: Jaguaruana: 16\%; Limoeiro do Norte: 14\%, Russas: 14\%; and Tabuleiro do Norte: $3 \%$ ). Majority of the patients also had a low level of education (63.3\% with elementary school education), and belonged to households that earned one to two times the minimum wages per month or less.

Other than benznidazole, 49 medications were identified, amounting to 128 medications, with most of them $(\mathrm{n}=54,41.4 \%)$ related to the cardiovascular system. Some patients reported having previous allergies to medications $(\mathrm{n}=3,10 \%)$, namely diclofenac, acetylsalicylic acid (ASA), and propranolol. No reports of food-related allergies were found.

The most used drug classes were agents against $\mathrm{CD}(\mathrm{n}=30)$; antithrombotic $(\mathrm{n}=9)$; angiotensin II receptor antagonists $(\mathrm{n}=7)$; thiazide diuretics $(n=7)$; angiotensin-converting enzyme (ACE) inhibitors and diuretics $(n=6)$; sulfonamide diuretics $(n=6)$; selective and non-selective beta blockers $(\mathrm{n}=5)$; proton-pump inhibitors $(\mathrm{n}=5)$; 3-hydroxy-3-methyl-glutaryl-coenzyme A (HMG-CoA) reductase inhibitors $(\mathrm{n}=5)$; and potassium-sparing agents $(n=4)$. The most used medications besides BNZ, were acetylsalicylic acid (ASA), losartan, hydrochlorothiazide, furosemide, captopril, and omeprazole.

\section{Benznidazole treatment compliance}

The results of this study indicate that 22 (73.3\%) patients were adherent to the treatment. The patients who did not comply with their therapies belonged to the age group of $\geq 60$ years and had low education levels. Two (6.7\%) patients who did not comply with the treatment had their therapies interrupted after medical evaluation. A statistically significant correlation between adherence and existence of DRPs was observed in the patients with $C D$ who were treated with $B N Z(p<0.0001)$, but no significant relationship was found between adherence and age range (Table 2).

\section{Drug-related problems}

A total of 189 DRPs were identified, with $51.9 \%(\mathrm{n}=98)$ considered to be potential DRPs [average of 3.2 potential DRPs/patient; standard deviation (SD) $=2.4344$ )] and 48.1\% $(\mathrm{n}=91)$ considered to be actual DRPs (average of 3 real DRPs/ patient; $\mathrm{SD}=3.8995$ ). Regarding the number of DRPs observed during treatment, the results showed that on average, the ratio of DRPs/patient was 6.3. Among all DRPs found $(n=189)$, most 
TABLE 2

Inferential analysis between adherence versus age range and adherence vs. DRP correlations in patients with CD treated with benznidazole.

\begin{tabular}{lcccc}
\hline $\begin{array}{l}\text { Treatment compliance (patient } \\
\text { characteristic) }\end{array}$ & $\mathbf{6 0 0}$ years & $\mathbf{2 6 0 \text { years }}$ & $\mathbf{<}$ DRP & $\mathbf{5}$ DRP \\
\hline Adherent & 9 & 13 & 14 & 5 \\
Non-adherent & 2 & 6 & $\mathbf{1 9}$ & $\mathbf{1 7}$ \\
\hline Total & $\mathbf{1 1}$ & $\mathbf{1 3}$ \\
\hline
\end{tabular}

DRPs: drug-related problems; CD: Chagas disease. Student's $t$ test and Fisher's exact test $(p>0.05)$ of adherence versus age range. Student's $t$ test $(p<0.0001)$ and Fisher's exact test ( $p>0.05$ ) of adherence versus DRP. Source: Compiled by the author.

TABLE 3

Descriptive analysis of the classification of DRPs of patients with CD treated with benznidazole - LPDC.

\begin{tabular}{lccc}
\hline Drug-related problems & Total & Per patient (\%) & Average/patient \\
\hline DRP 1* & 52 & 27.5 & 1.7 \\
DRP 2* & 15 & 7.9 & 0.5 \\
DRP 3** & 45 & 23.8 & 3.5 \\
DRP 4** & 7 & 3.7 & 0.2 \\
DRP 5*** & 70 & 37.0. & 2.3 \\
DRP 6*** & 0 & 0.0 & 0 \\
\hline Total & $\mathbf{1 8 9}$ & $\mathbf{1 0 0 . 0}$ & $\mathbf{6 . 3}$ \\
\hline
\end{tabular}

DRPs: drug-related problems; CD: Chagas disease; LPDC: Research Laboratory of Chagas Disease. *DRP related to necessity. **DRP related to effectiveness. ***DRP related to safety. Source: Compiled by the author.

TABLE 4

Descriptive analysis of the PIs conducted during the pharmacotherapeutic follow-up of patients with CD treated with benznidazole.

\begin{tabular}{|c|c|c|c|c|}
\hline Classification of the PIs & Examples of PIs & Total & Per PI (\%) & Average/patient \\
\hline Pharmacological strategy & $\begin{array}{c}\text { Inclusion of a new medication, through medical prescription; } \\
\text { abandoning of a medication; suspension a medication } \\
\text { following medical orders. }\end{array}$ & 42 & 19.4 & 1.4 \\
\hline Medication quantity prescribed & $\begin{array}{l}\text { Modification of the schedules under which medications are } \\
\text { taken throughout the day. }\end{array}$ & 6 & 2.8 & 0.2 \\
\hline Total & & 216 & 100.0 & 7.2 \\
\hline
\end{tabular}

PIs: pharmaceutical interventions; CD: Chagas disease. Source: Compiled by the author.

were classified as problems associated with efficacy (DRP 5: $37 \% ; \mathrm{n}=70$ ), followed by problems related to necessity (DRP 1: $27.5 \% ; n=52)$, and safety (DRP 3: 23.8\%; $n=45$ ) (Table 3).

\section{Pharmaceutical interventions}

Among the 216 PIs that occurred, 168 (77.8\%) were related to patient education, $42(19.4 \%)$ were related to pharmacological strategy, and six $(2.8 \%)$ were related to the prescribed medication dose. Since the interventions were outcomes of DRPs, no statistical analyses were applied (Table 4).

\section{DISCUSSION}

To establish an adequate and specific treatment for patients with $\mathrm{CD}$, physicians and pharmacists must know the patients' biopsychosocial characteristics, medication use, as well as the difficulties that can often accompany pharmacotherapy ${ }^{10}$. In this study, the majority of patients were elderly, with low education, and low family income. These characteristics can serve as barriers to good adherence to treatment, and can contribute to observed DRPs. Therefore, pharmacotherapeutic monitoring can be useful to reduce these problems and provide the patient with a better quality of life $\mathrm{e}^{10-13}$.

Among the patients enrolled in this study, the most used medications, besides benznidazole, were ASA, losartan, hydrochlorothiazide, furosemide, captopril, and omeprazole. These drugs were mostly administered to treat the conditions of the studied population, which was predominantly in the age range of $\geq 60$-years. With its antithrombotic effect, ASA can be 
used both as a painkiller and to treat coronary artery disease resulting from atherosclerosis. The remaining drugs - losartan, furosemide, and captopril - is used in antihypertensive therapy ${ }^{16}$. The use of omeprazole may be justified by gastroesophageal reflux disease or dyspepsia, depending on whether or not the patient has stress daily or poor dietary habits. Thus, these factors could be solved with better diet habits or even through an improved lifestyle ${ }^{17,18}$.

Pontes et al. ${ }^{19}$ found that among the 32 patients in their study, 10 (32\%) reported using other medications (antihypertensive drugs, diuretic drugs, calcium channel blockers, and antihyperlipidemic agents) along with benznidazole ${ }^{19}$. In turn, Souza-Júnior et al. ${ }^{13}$ found that $42 \%$ of their patients used two or three more medications during their BNZ therapies, with an observed average of 1.3 drugs/patient, most of which were administered for hypertension ${ }^{13}$. The findings of this study about the pharmacological classes were concordant with other studies. Further, patients of older age and who simultaneously use several medications require more careful attention to drug and non-drug treatments.

In this study, most patients were found to comply with their BNZ treatment. Non-adherence seems to be significantly correlated to treatment suspension because of DRPs that were observed after medical evaluation. Souza-Júnior et al. ${ }^{13}$ and Pontes et al. ${ }^{19}$ also observed several cases of BNZ treatment suspension in the patients they monitored ${ }^{13,19}$. According to the WHO (2003), non-adherence is one of the main reasons why treatment goals are not achieved ${ }^{20}$. In addition, non-adherence leads to psychological and medical complications, decreased quality of life, and waste of health care funds.

However, despite all the difficulties faced by these patients (age-related negative physiological conditions, socioeconomic problems, presence of comorbidities, polypharmacy, etc), the patients were still considered adherent to treatment. This suggests that the process through which these patients were treated by pharmacists may be relevant to the management of the proposed pharmacotherapy. Thus, the relationship established between pharmacists and patients, by sharing responsibilities and by respecting their individual characteristics and needs, may favor patient adherence. Pharmaceutical care promotes strategies and interventions to ensure patient compliance with the treatment prescribed ${ }^{12,13,19}$.

In this study, patients over 60-years-old were not likely to terminate treatment. According to some authors, adherence to treatment can be observed during the service provided and it is possible to identify failures that can affect the confidence that the patient places in the prescriber, in the pharmacist who advises the use of the prescribed medication, and in the treatment as a whole ${ }^{21}$.

A direct relationship was found between the number of DRPs and the number of medications taken per patient. Patients who took more than five medications were observed to be more likely (three times) to have DRPs. The results identified 189 DRPs, especially those regarding DRP 5 (non-quantitative unsafety).

Studies involving the monitoring of patients with CD are scarce. Specifically, this group has been pioneering the publication of articles in this context of pharmacotherapeutic follow-up and pharmacist engagement in CD treatment ${ }^{13,18,20}$. Further, Souza-Júnior et al. ${ }^{13}$ found similar results in their study that was conducted over the first years of this research group's pharmaceutical care service. A total of 148 DRPs were identified, where $41.9 \%$ (62) were related to necessity, $33.1 \%$ (49) were related to effectiveness, and 25\% (37) were related to safety. Comparing these results to the current study's findings, a change was observed in the DRP profile, which may imply an improvement in this research group's care procedures and in the prevention of medication use ${ }^{13}$.

The majority of these DRPs were related to BNZ toxicity, possible drug interactions, and non-adherence or other medications, such as hydrochlorothiazide and anxiolytic agents. In addition, many patients had untreated conditions, such as uncontrolled systemic arterial hypertension, chronic inflammatory diseases, or diabetes, as observed by the number of DRPs related to necessity. Further, patients vary on their access to basic health care units, as most patients have modest financial means, come from countryside regions, and have no health insurance ${ }^{22}$.

This study found a predominance of DRP 5 (adverse reactions), followed by DRP 1 (untreated health problems). Besides BNZ, other medications used by the patients during their treatments caused this type of DRP, such as furosemide, warfarin, captopril, digoxin, and anxiolytic agents. The adverse effects related to these medications included increased urinary frequency, nausea, dizziness, and abdominal pain, with one or more related symptoms potentially being present. In turn, the adverse effects related to BNZ were dermatopathies, neuropathies, abdominal pain, and itching, among others. The clinical circumstances that can generate a DRP may be related to the drug itself, to the patient, to whoever prescribes the drug, to the pharmacist, or to the health care system ${ }^{23}$. These causes may be controlled or avoided by analyzing the processes through which the medications are used, quality indicators are used, and the correction of significant risks ${ }^{24}$. This can be done by the entire health care team and it requires a paradigm shift towards greater concern of medication usage ${ }^{25}$.

Almost half of the patients in this study reported having BNZ-related health problems. Among these, only two had hypersensitivity reactions with skin symptoms. The most frequent reactions to BNZ were dizziness, lack of appetite, stomach pains, nausea, paresthesia on the hands or feet, and loss of taste. According to the II Brazilian Consensus on Chagas Disease (2015), around 30\% of BNZ users have adverse reactions ${ }^{9}$.

The study conducted by Pontes et al. ${ }^{19}$ corroborates the current study's findings. Among the 32 patients undergoing BNZ treatment, $87.5 \%$ were found to have some sort of adverse reaction, and $25 \%$ had their treatments suspended. The most frequent symptoms were itching, paresthesia, asthenia, rash, and skin peeling ${ }^{19}$.

Regarding the necessity-related DRPs, this study observed instances where the presence of health problems required drugs to alleviate the ailment or alleviate the symptoms. The lack of 
orientation and access to basic health care services show the importance of health care professionals in avoiding this kind of problem. Another aspect important to the development of DRPs is self-medication and medication misuse, which must be thwarted through adequate interventions.

The cases regarding DRP 3 were mainly to the result of the BNZ users taking the drug in doses prescribed as recommended by the II Brazilian Consensus on Chagas Disease (2015); that is, $5 \mathrm{mg} / \mathrm{kg}$ a day. However, it is difficult to assess the final effectiveness of this dosage without expressive clinical results of parasitological healing ${ }^{9,26}$.

Benznidazole has limited effectiveness during the chronic phase of CD. However, as suggested by the II Brazilian Consensus on Chagas Disease (2015), even though there are discrepancies regarding cure percentages for the etiological treatment, there is a consensus on its usefulness, depending on circumstances such as disease phase, patient age, and associated conditions. Confirmed cure during the chronic phase depends on several factors, such as follow-up time and types of exams conducted ${ }^{9}$.

Recently, The Benznidazole Evaluation for Interrupting Trypanosomiasis (BENEFIT) study showed that treatment with benznidazole did not reduce cardiac disease progression in patients with established cardiomyopathy, although the drug was significantly able to reduce parasite detection through polymerase chain reaction (PCR). However, the study also pointed to a therapy discontinuation rate of $13.4 \%$, which although lower than the rates found in most other studies was more than double than the rate found in the present study. These results could be related to the high number of adverse reactions and other problems experienced during the treatment with benznidazole. Thus, pharmacotherapeutic follow-up and pharmaceutical care could be a good option for decreasing treatment discontinuation through DRP identification and $\mathrm{PI}^{27}$.

In this study, an average of 7.2 pharmaceutical interventions/ patient was conducted during pharmacotherapeutic followup. The majority of observed DRPs were related to patient education, which is fundamental for satisfactory therapy and for improving a patient's quality of life, especially when considering the low education level of this study's population. The main interventions regarding education were related to a healthier lifestyle, such as daily water intake, the importance of good dietary habits, and the promotion of physical activity. This type of intervention has been shown to improve the quality of life of patients with heart failure, diabetes, hypertension, and dyslipidemia, as demonstrated by several studies investigating proper patient care $\mathrm{c}^{28-31}$.

The costs associated with drug-related morbidity and mortality is highly relevant to health care system managers, patients, and the society as a whole ${ }^{32}$. The direct and indirect roles of pharmacists may avoid the misspending of funds by preventing and correcting DRPs. According to Hepler and Strand (1990), preventable drug-related morbidity is a problem within many health care systems. Improper pharmacotherapy results must be prevented through a clinical and humanitarian perspective. The financial resources spent on predictable drug- related morbidity are immense, thus correcting the problem will not only reduce spending, but also enable other interventions in the health care system to be used for greater efficacy and outcomes $^{10}$. Such an approach can be applied to how patients with $\mathrm{CD}$ are treated and managed.

In this study, patients with $\mathrm{CD}$ were considered to be adherent to their benznidazole treatment despite having low education levels and coming from underprivileged regions. Non-adherence was found to be associated with DRPs. Adverse reactions were the main DRPs identified, along with untreated comorbidities. PIs were conducted to prevent and/or solve the observed DRPs, which allowed pharmacists to be actively engaged in the clinical care, health promotion, and education of the patients with $\mathrm{CD}$.

\section{Acknowledgements}

This study thanks the team at the Research Laboratory of Chagas disease (LDPC) for performing the monitoring of patients with CD in the state of Ceara and the study center in Pharmaceutical care (CEATENF) of the Federal University of Ceara (UFC), who gave full support to the pharmacotherapeutic follow-up of these patients.

\section{Financial Support}

This study was supported by the Cearense Foundation for the Support of Scientific and Technological Development (FUNCAP) and the Federal University of Ceará (UFC).

\section{Conflict of interest}

The authors declare that there is no conflict of interest.

\section{REFERENCES}

1. Schmunis GA, Yadon ZE. Chagas' disease: a Latin American health problem becoming a world health problem. Acta Trop. 2010;115 (1-2):14-21.

2. World Health Organization. Chagas' disease (American trypanosomiasis): fact sheet (revised in June 2010). Wkly Epidemiol Rec. 2010;85(34):334-6.

3. Organización Panamericana de la Salud. Estimación cuantitativa de la enfermedad de Chagas en las Américas. Document OPS/HDM/ CD/425.06, Washington: DC 2006. 29p.

4. Coura JR, Dias JCP. Epidemiology, control and surveillance of Chagas disease - 100 years after its discovery. Mem Inst Oswaldo Cruz. 2009; 104(suppl I): 31-40.

5. World Health Organization. Chagas disease (American trypanosomiasis): fact sheet (revised in August 2012). Wkly Epidemiol Rec. 2012;87(51/52):519-22.

6. Centers for Disease Control and Prevention. Parasites - American Trypanosomiasis (also known as Chagas Disease). Epidemiology \& Risk Factors [Internet].2013 Jul 19. [updated 2015 Jul 8; cited 2015 Jul 9]. Available from: http://www.cdc.gov/parasites/chagas/epi.html.

7. Guedes PMM, Fietto JRL, Lana M, Bahia MT. Advances in Chagas disease chemotherapy. Antiinfect Agents Med Chem. 2006;5(2):175-86.

8. Carrilero B, Murcia L, Martinez-Lage L, Segovia M. Side effects of benznidazole treatment in a cohort of patients with Chagas disease in non-endemic country. Rev Esp Quimiot. 2011;24(3):123-26. 
9. Dias JCP, Ramos Jr AN, Gontijo ED, Luquetti A, Shiknai-Yasuda MA, Coura JR, et al. II Consenso Brasileiro em doença de Chagas, 2015. Epidemiol Serv Saúde. 2016;25(n.esp):7-86.

10. Hepler CD, Strand LM. Oportunidades y responsabilidades en la Atención Farmacêutica. Pharm Care Esp. 1999;1:35-47.

11. Santos H, Iglésias P, Fernández-llimós F, Faus MJ, Rodrigues LM. Segundo Consenso de Granada sobre problemas relacionados com medicamentos. Acta Med Port. 2004;17:56-66.

12. Hernández DS, Castro MMS, Dáder MJF. Método Dáder: Manual de Seguimento Farmacoterapêutico. $3^{\mathrm{a}}$ edição. Alfenas: Editora Universidade Federal de Alfenas; 2014. 128p.

13. Souza-Júnior AS, Coelho HLL, de França Fonteles MM, Oliveira MF. Problemas relacionados a medicamentos em pacientes com doença de Chagas durante tratamento com benzonidazol em Fortaleza - CE. Cad Saúde Colet. 2009;17(4):893-909.

14. Sabater D, Fernández-Llimós F, Parras M, Faus MJ. Tipos de intervenciones farmacéuticas en seguimiento farmacoterapéutico. Seguim Farmacoterap. 2005;3(2):90-7.

15. Moreira LB, Fernandes-PFCBC, Monte FS, Galvão IM, Martins AMC. Conhecimento sobre o tratamento farmacológico em pacientes com doença renal crônica. Rev Bras Ciênc Farmac. 2008; 44(2):315-325.

16. Piegas LS, Timerman A, Feitosa G, Rossi Neto JM, Nicolau JC, Mattos LA, et al. Sociedade Brasileira de Cardiologia. IV Diretriz da Sociedade Brasileira de Cardiologia sobre Tratamento do Infarto agudo do Miocárdio com Supradesnível do Segmento ST. Arq Bras Cardiol. 2009;93(6 supl 2):e179-e264.

17. Silva FM. Dispepsia: caracterização e abordagem. Rev Med. 2008;87(4):213-23.

18. Aizenstein ML, Tomassi MH. Problemas relacionados a medicamentos; reações adversas a medicamentos e erros de medicação: a necessidade de uma padronização nas definições e classificações. Rev Ciênc Farm Básica Apl. 2011;32(2):169-73.

19. Pontes VMO, Souza Júnior AS, Cruz FMT, Coelho HLL, Dias ATN, Coelho ICB, et al. Reações adversas em pacientes com doença de Chagas tratados com benzonidazol, no Estado do Ceará. Rev Soc Bras Med Trop. 2010;43(2):182-7.

20. Pereira LS, Freitas EC, Fidalgo ASOBV, Andrade MC, Cândido DS, da Silva Filho JD, et al. Clinical and epidemiological profile of elderly patients with Chagas disease followed between 2005-2013 by pharmaceutical care service in Ceará State, Northeastern Brazil. Rev Inst Med Trop São Paulo. 2015;57(2):145-52.

21. Marinker M, Shaw J. Not to be taken as directed: putting concordance for taking medicines into practice. BMJ. 2003;326(7385):348-9.

22. Storino, R, Auger S, Wojdyla D, Urrutia MI, Jörg M. Análisis descriptivo multivariado de la enfermedad de Chagas en 2260 pacientes. Rev Argent Cardiol. 1998;66(1):17-39.

23. Correr CJ, Pontarolo R, Ferreira LC, Baptistão SAM. Riscos de problemas relacionados com medicamentos em pacientes de uma instituição geriátrica. Rev Bras Ciênc Farmac. 2007;43(1):55-62.

24. Morris CJ, Cantrill JA. Preventing drug-related morbidity - the development of quality indicators. J Clin Pharm Ther. 2003;28(4):295-305.

25. Rosa MB, Perini E. Erros de medicação: quem foi? Rev Assoc Med Bras. 2003;49(3):335-41.

26. Ministério da Saúde. Agência Nacional de Vigilância Sanitária. Lei 5.991, de 17 de dezembro de 1973. Dispõe sobre o controle sanitário do comércio de drogas, medicamentos, insumos farmacêuticos e correlatos e dá outras providências. Diário Oficial da União, $21 \mathrm{dez}$ 1973; Seção 1:13182. [Internet]. [updated 2015 Jul 8; cited 2015 Jul 9]. Available from: http:// www.anvisa.gov.br./legis/5991_73thm.

27. Morillo CA, Marin-Neto JA, Avezum A, Sosa-Estani S, Rassi Jr A, Rosas F, et al. Randomized Trial of Benznidazole for Chronic Chagas' Cardiomyopathy. N Engl J Med. 2015;373(14):1295-1306.

28. Skaer TL, Sclar DA, Markowski DJ, Won JK. Effect of value-added utilities on prescription refill compliance and Medicaid health care expenditures - a study of patients with non-insulin-dependente diabetes mellitus. J Clin Pharm Ther. 1993;18(4): 295-9.

29. Van Veldhuizen MK, Widmer LB, Stacey SA, Popovich NG. Developing and implementing a pharmaceutical care model in an ambulatory care setting for patients with diabetes. Diabetes Educ. 1995;21(2):117-23.

30. Jaber LA, Halapy H, Fernet M, Tummalapalli S, Diwakaran H. Evaluatiion of a pharmaceutical care model on diabetes management. Ann Pharmacother. 1996;30(3):238-43.

31. Varma S, McElnay JC, Hughes CM, Passmore AP, Varma, M. Pharmaceutical care of patients with congestive heart failure: interventions and outcomes. Pharmacotherapy. 1999;19(7):860-9.

32. Johnson JA, Bootman JL. Drug-related morbidity and mortality. A cost-of-illness model. Arch Intern Med. 1995;155(18):1949-56. 